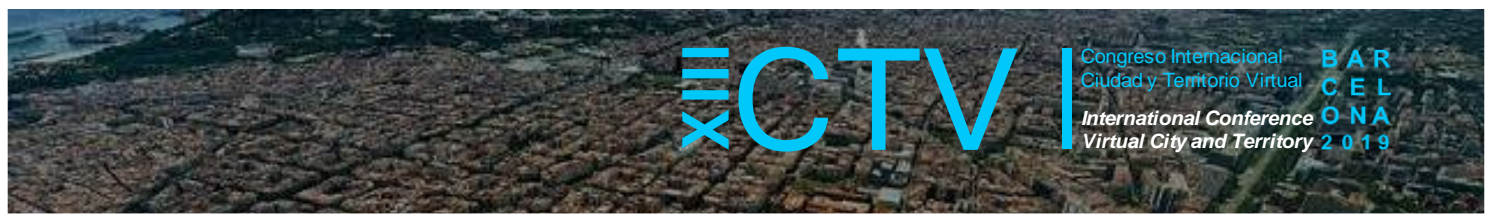

\title{
PROSPECTIVA AMBIENTAL PARA LA LAGUNA DE TRES PALOS, MUNICIPIO DE ACAPULCO, GUERRERO, MÉXICO.
}

\author{
Juárez, Lissette ${ }^{1 *}$ Rodríguez, Columba ${ }^{2}$; Castro, Mirna ${ }^{3}$, Aparicio, José Luis ${ }^{4}$, Marmolejo, \\ Carlos V. ${ }^{5}$
}

Remisión inicial: 2019-06-16; Remisión definitiva: 2019-10-20; Publicación: 2019-12-21
Citación: Juárez, L. et al. (2019). Prospectiva Ambiental para la Laguna de Tres Palos, Municipio de Acapulco, Guerrero, México. En XIII CTV 2019 Proceedings: XIII International Conference on Virtual City and Territory: "Challenges and paradigms of the contemporary city": UPC, Barcelona, October 2-4, 2019. Barcelona: CPSV, 2019, p. 8610. E-ISSN 2604-6512. DOI http://dx.doi.org/10.5821/ctv.8610

Resumen

La laguna de Tres Palos en Acapulco, Guerrero, México, es un cuerpo de agua dulce que, además de la biodiversidad que alberga y los beneficios ecológicos que genera, sirve de sustento a las poblaciones aledañas. Actualmente, la contaminación del agua afecta las actividades económicas como la pesca y el turismo. El objetivo fue realizar una caracterización física-química y socioeconómica de la Laguna de Tres Palos para un análisis complejo de la problemática y su prospectiva en la actividad pesquera. Se desarrollaron cuatro etapas: reconocimiento de la Laguna, caracterización ambiental y socioeconómica, análisis de la problemática y evaluación de series de tiempo para la actividad pesquera; se utilizaron sonda marina, GPS, termómetro y equipo de laboratorio; el procesamiento estadístico se hizo en Excel, Minitab y el cartográfico en ArcGis. Se encontraron condiciones de pobreza y marginación en la población, principalmente en Candelilla y Varadero de Tres palos. Las actividades económicas principales son la pesca, la agricultura y el turismo. Se identificaron tres zonas: la desembocadura del Río de la Sabana, es somera y presenta mayor turbiedad con la entrada del afluente y aporte de materia orgánica, así como residuos sólidos; la zona norte presenta una mayor corriente, por lo que la salinidad es baja, así como el promedio de la temperatura; y la zona sur, con menor grado de eutrofización y mayor vegetación, y por ser la más cercana al canal que conecta con el mar, tiene alta conductividad en función de los SDT y la salinidad. La problemática ambiental se agudiza por la deforestación de manglar, el azolvamiento y la sobrepesca; las aguas vertidas por el Río de la Sabana representan la principal fuente de contaminación de la laguna. El futuro de la pesca es incierto, las especies de mayor valor comercial como lisa (Mugil curema) y el robalo (Centropomus nigriscens), continuarán disminuyendo, mientras las especies más resistentes como la tilapia (Oreochromis niloticus), que se produce en granjas acuícolas irá en aumento. Se concluye que hay conflicto entre actores y debilidad de las instituciones en el cumplimiento de políticas; la Laguna de Tres Palos requiere de una gobernanza ambiental eficiente.

\begin{abstract}
The Tres Palos lagoon in Acapulco, Guerrero, Mexico, is a shallow inland water body that, in addition to the biodiversity it contains and the ecological benefits it generates, serves as sustenance for the surrounding towns. Currently, water pollution affects economic activities such as fishing and tourism. The objective was to construct a physical and socioeconomic characterization of the Tres Palos Lagoon for a complexity analysis of the problem and its prospective in fishing activity. Four stages were developed: recognition of the Lagoon, environmental and socioeconomic characterization, analysis of the problem and evaluation of time series for fishing activity; marine probe, GPS, thermometer and laboratory equipment were used; statistical processing was done in Excel, Minitab and cartographic in ArcGis. Poverty is a general condition along the communities studied. The main economic activities are fishing, agriculture and tourism. As a result of the chemical analysis three zones were identified: the limits with Río de la Sabana, which is shallow and presents the greatest turbidity with the entrance of sewage water and solid waste; the north zone presents a greater current, so the salinity is low, as well as the average temperature; and the southern zone, with a lower degree of eutrophication and greater vegetation presents high conductivity depending on salinity. The
\end{abstract}

\footnotetext{
${ }^{1}$ CCDR, Universidad Autónoma de Guerrero, https://orcid.org/0000-0002-7646-7243; ${ }^{2}$ CCDR, Universidad Autónoma de Guerrero, https://orcid.org/0000-0001-9600-8776; ${ }^{3}$ Instituto Tecnológico de Chilpancingo, https://orcid.org/00000002-0826-5535; ${ }^{4}$ CCDR, Universidad Autónoma de Guerrero, https://orcid.org/0000-0002-4586-6954; ${ }^{5}$ Instituto Tecnológico de Chilpancingo, https://orcid.org/0000-0002-2027-5664. *Correo de contacto: lii 27@hotmail.com
} 


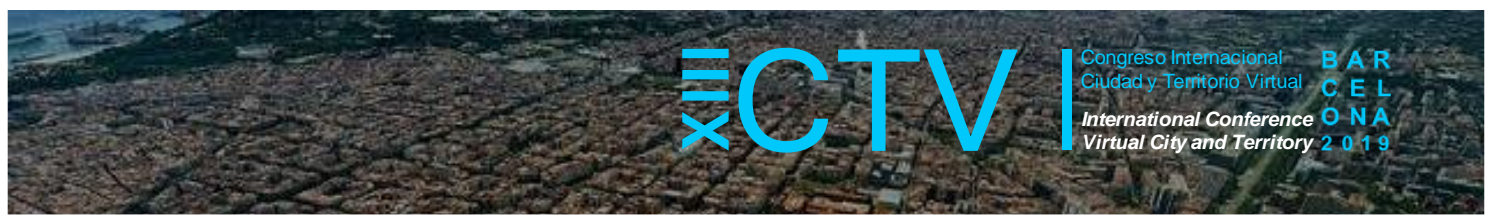

environmental problem is exacerbated by mangrove deforestation, dusting and overfishing; The waters discharged by the Río de la Sabana represent the main source of pollution in the lagoon. The future of fishing production is uncertain, species of greater commercial value such as robalo (centropomus nigriscens) is declining, while more resistant species such as tilapia (oreochromis niloticus) is produced in aquaculture farms will increase. It is concluded that there is conflict between actors and weakness of the institutions in the fulfillment of policies; the Laguna de Tres Palos requires efficient environmental governance.

Palabras Clave: laguna costera; prospectiva ambiental; sostenibilidad; gobernanza

Key words: lagoon; strategic foresight; sustaintability; governance

\section{Introducción}

Las lagunas costeras son ambientes altamente amenazados a nivel mundial debido principalmente a las acciones del ser humano que se relacionan con la extracción del agua, el crecimiento urbano, el relleno de estos espacios para transformarlos en terrenos habitacionales o en muchos casos, su uso como sumideros de basura. Además, la falta de información y la escasa conciencia sobre la importancia de estos ambientes hace aún más difícil su protección.

En México, $73 \%$ de los cuerpos de agua están contaminados y $80 \%$ de las descargas de los centros urbanos e industriales se vierten sin tratamiento previo; esto pone en riesgo el equilibrio de su biodiversidad y la pérdida de servicios ecosistémicos (CONAGUA, 2012; Lara-Lara et al, 2008; citados por Ruiz, 2017). Lo anterior permite cuestionarse cuál será su situación en las próximas décadas.

La problemática a la que conducen los factores antrópicos genera una alta presión sobre los humedales con consecuencias ambientales, sociales y económicas (Senhadji-Navarro, et al., 2017) y Pires et al., 2017). Estudios realizados en la década de los años setenta del siglo pasado señalan el creciente problema de eutrofización de la Laguna. De la Lanza (2008) se propone contrastar la calidad ambiental y el estado trófico de la laguna evaluada en 1971, mediante parámetros fisicoquímicos y biológicos. La condición de hipoxia y anoxia en el fondo permaneció; sin embargo, otras características como la densidad de fitoplancton y florecimiento de cianófitas ocasionaron que la condición de eutrófica cambiara a hipertrófica treinta y dos años después.

Con la degradación del cuerpo de agua ocurre algo cercano a lo que Anthony Giddens (2010) señala como "la paradoja Giddens" del cambio climático, donde debido a que los peligros no son tangibles, inmediatos o visibles en la vida cotidiana, la mayoría de la gente no hará nada, incluso, existiendo evidencias científicas. En el caso de la laguna, los efectos sí son tangibles, pero sólo para las comunidades pesqueras que habitan alrededor. El resto de la población del municipio de Acapulco se muestra indiferente ante el problema ambiental.

Godet (2007) establece que el mundo cambia, pero los problemas permanecen y se agravan. La prospectiva es un método que permite construir escenarios a través de alternativas de planeación estratégica, posibilita transitar de futuros especulatorios a unos anticipados y creados (Jones, 2017), donde la sostenibilidad sea el eje para el bienestar social y la gobernabilidad un factor transversal para generar condiciones favorables que la alienten. Adicionalmente, la implementación de políticas adecuadas pueda prevenir los efectos del cambio climático, generar servicios ambientales y potenciar beneficios socioeconómicos (Pires et al., 2017). 


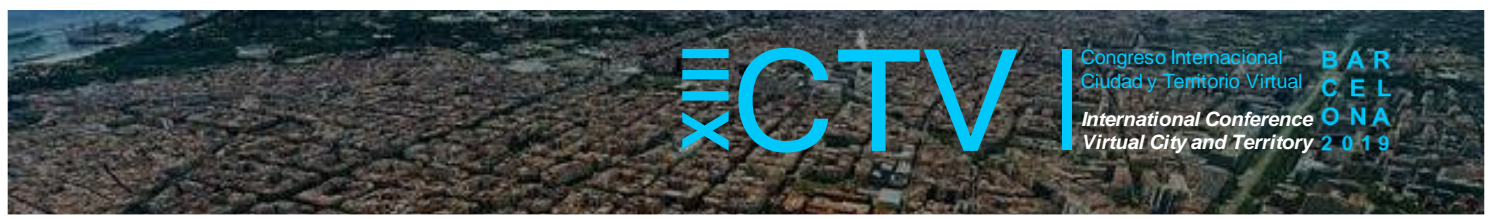

Es necesario plantear el problema a través de una propuesta que analice el ambiente con base en la teoría de sistemas y entender la problemática ambiental de la Laguna de Tres Palos, desde el reconocimiento de las relaciones entre los elementos de la naturaleza (físicos, químicos y biológicos) con el ser humano y la sociedad, como una estructura política, social, cultural y económica; mediante cuatro fases metodológicas1) reconocimiento de la Laguna con visitas exploratorias, entrevistas y revisión bibliográfica; 2) caracterización socioeconómica y física-química (análisis correlacional y multivariado de variables) ; análisis de la problemática, y evaluación de series de tiempo para la producción pesquera. El objetivo fue realizar una caracterización física-química y socioeconómica de la Laguna de Tres Palos para un análisis complejo de la problemática y su prospectiva en la actividad pesquera.

\section{Metodología}

\section{1 Área de estudio}

La Laguna de Tres Palos está ubicada a $25 \mathrm{~km}$ al este del puerto de Acapulco en el estado de Guerrero, México, entre 99 $39^{\prime}$ y $99^{\circ} 47^{\prime}$ de longitud Oeste y $16^{\circ} 47^{\prime}$ y $16^{\circ} 49^{\prime}$ de latitud Norte, con superficie aproximada de 5500 ha, dimensiones de $16 \mathrm{~km}$ de longitud por $6 \mathrm{~km}$ de ancho. La laguna se clasifica como predominantemente oligohalina, con influencia marina en época de avenida, cuando se abre el canal de comunicación con el mar en el poblado de Barra Vieja (Rosas et al, 2016, Ortiz, 2014; Mendoza et al, 2013). En función de la clasificación climática de Köppen y las modificaciones para México realizadas por García (1973), la laguna presenta un clima Aw1, subhúmedo, su temperatura es caliente todo el año, el mes más frío registra una temperatura no menor a $18^{\circ} \mathrm{C}$; la precipitación pluvial anual es mayor de $1000 \mathrm{~mm}$ y la lluvia invernal es menor a $50 \mathrm{~mm}$. El régimen pluviométrico que caracteriza a esta zona pertenece al de la sabana o de lluvias de verano.

\subsection{Metodología}

El planteamiento metodológico se describe de manera general en la figura 1.

Figura 1. Esquema metodológico

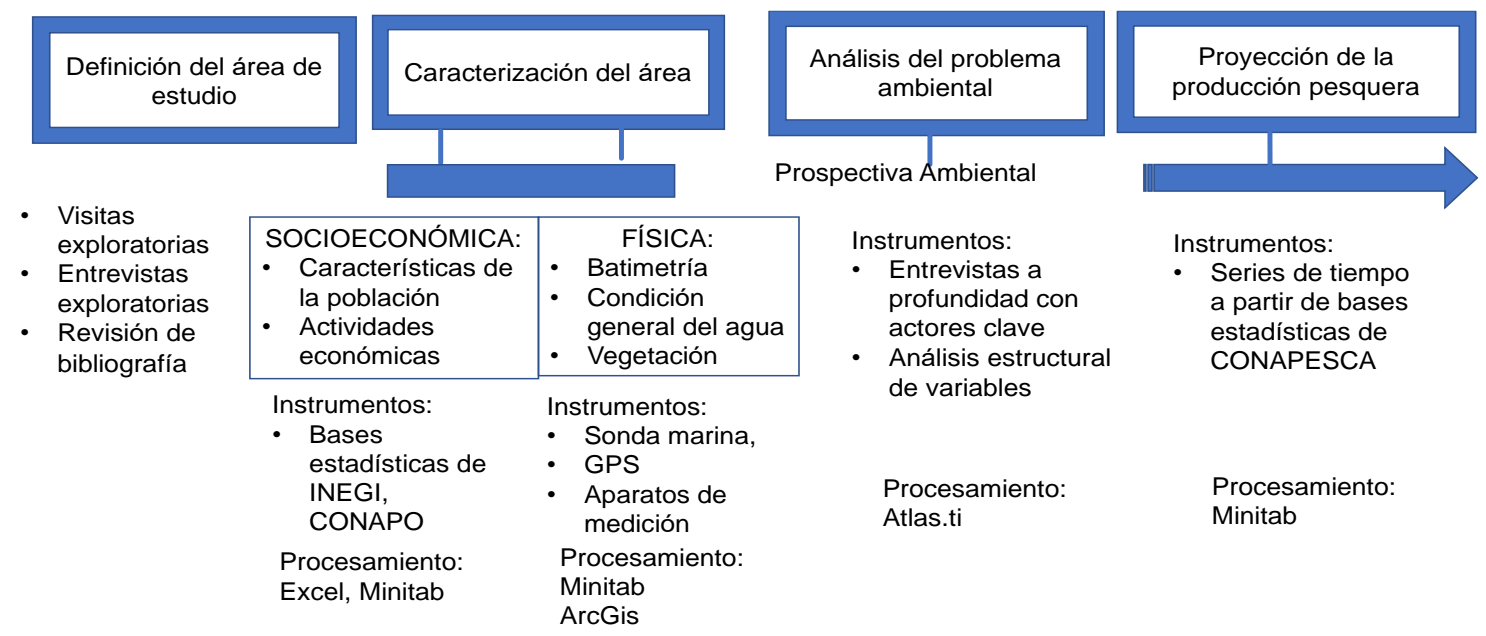

Fuente: Elaboración propia 


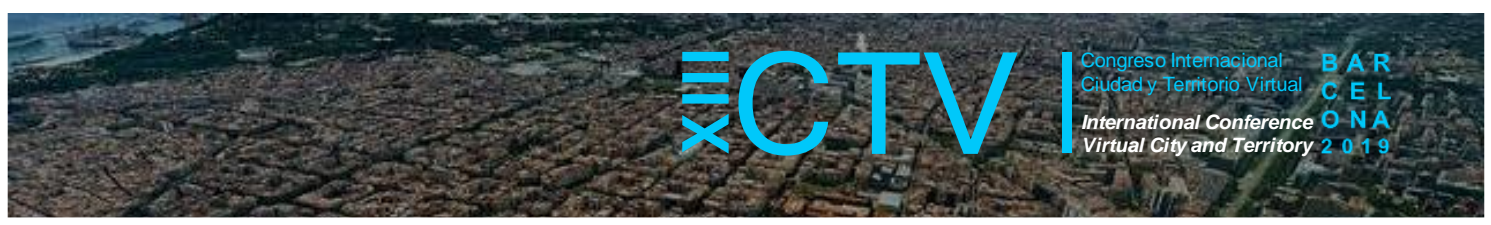

A. Reconocimiento del área de estudio

Se realizaron visitas exploratorias en las localidades de San Pedro Las Playas, Varadero de Tres Palos y Barra Vieja, donde a través de la observación y pláticas informales con los pescadores, presidentes de cooperativas y prestadores de servicios turísticos, se identificaron a los actores que operan a diferentes niveles espaciales, sus intereses, sus relaciones con el medio, así como los conflictos resultantes.

\section{B. Caracterización socioambiental y física de la laguna}

Para la caracterización socioambiental del área de estudio, se construyeron bases de datos por localidad sobre población, salud, educación y vivienda (INEGI, 2010); marginación (CONAPO, 2010); y producción pesquera (Gil, 2005; CONAPESCA, 2018). Los datos se procesaron y analizaron en los programas Excely Minitab.

Para el estudio de la batimetría, se seccionó el mapa de la laguna (trazando líneas paralelas a lo largo y ancho para la toma de datos cada 100 metros, con una sonda marina se midió la profundidad, la temperatura del agua y la descripción del fondo de acuerdo con las coordenadas geográficas previamente trazadas. La información se recabó durante tres visitas los días 28 de febrero, 5 y 13 de marzo de 2019, cuando las condiciones meteorológicas y de logística con los pescadores locales lo permitieron.

Se realizaron análisis químicos de veinte muestras de agua con parámetros de campo. La salinidad se midió con el método potenciométrico; la conductividad eléctrica se midió en microsiemens $(\mathrm{mu} / \mathrm{cm})$; los sólidos disueltos totales (SDT) se determinaron con el método electrométrico en miligramos por litro $(\mathrm{mg} / \mathrm{l})$; la turbiedad se estimó con el método colorimétrico en unidades nefelométricas (UTN); la temperatura en grados centígrados $\left({ }^{\circ} \mathrm{C}\right)$; y el potencial de hidrógeno $(\mathrm{pH})$ con el método potenciométrico, en una escala de 0 a 14.

Posteriormente, se compararon los valores medios para determinar si alguno de ellos difería significativamente del resto, se utilizó un análisis de varianza (ANOVA) con la siguiente estrategia: si los resultados obtenidos no contienen errores sistemáticos, los valores medios respectivos no diferirán mucho entre sí y su dispersión tampoco, debido a los errores aleatorios; es, por tanto, comparable a la dispersión presente individual en todas las zonas del cuerpo hídrico. Se procedió a descomponer la variabilidad total de los resultados en dos fuentes de variación: la debida a los resultados de campo y la debida a la precisión dentro de cada prueba.

Planteamiento

$$
\begin{aligned}
& \text { Ho: } \mu_{1}=\mu_{2}=\mu_{3} \\
& H_{1}: \text { Al menos una } \mu_{k} \neq 0 \quad \quad k=1,2 \text { y } 3 \text { (número de tratamientos o muestras) }
\end{aligned}
$$

Para determinar los valores de aceptación y de rechazo se fijó el nivel de significancia $\alpha$ de la prueba:

$$
\alpha=10 \% \circ 0.1
$$

Se encontró el valor crítico para el modelo del parámetro temperatura:

$$
\mathrm{F}_{\mathrm{k}-1, \mathrm{n}-\mathrm{k}, \alpha}
$$

Matemáticamente, la suma de cuadrados total, $\mathrm{SS}_{\mathrm{T}}$, se descompone como una suma de dos sumas de cuadrados:

$$
S S_{T}=S S_{R}+S S_{M}
$$




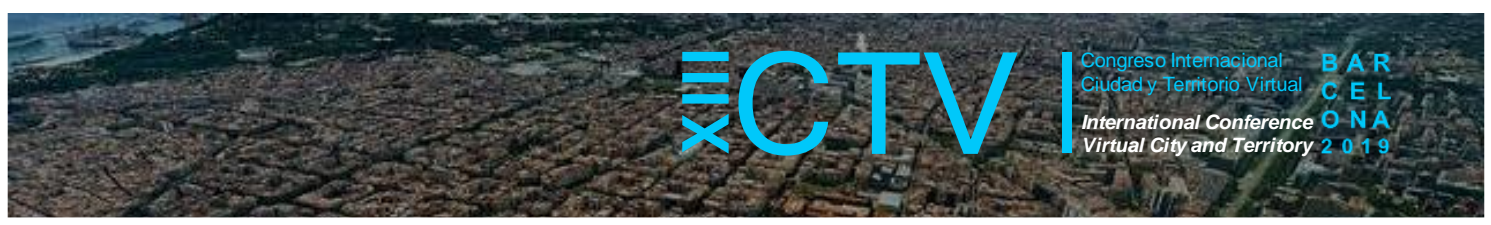

Donde $\mathrm{SS}_{\mathrm{T}}$ representa la variación total de los datos, $\mathrm{SS}_{\mathrm{R}}$, es una medida de la dispersión de los resultados por zona de la laguna, y $S_{\mathrm{M}}$ constituye el cuadrado medio entre las zonas de la laguna.

$\mathrm{SS}_{\mathrm{T}}$ es la suma de las diferencias al cuadrado de cada resultado individual respecto a la media de todos los resultados. $S S_{R}$ mide las desviaciones entre los resultados individuales $\left(X_{k j}\right)$, de cada muestra por zona (donde j indica el número de repetición) y la media de los tratamientos $\left(X_{k}\right)$. Cuando se divide $S S_{E}$ por los correspondientes grados de libertad, $(n-k)$, se obtiene el cuadrado medio (MS) dentro de los resultados, $\mathrm{MS}_{\mathrm{R}}$. Por otro lado, $\mathrm{SS}_{\mathrm{M}}$ mide las desviaciones entre los resultados medios de los resultados por zona y el resultado medio global y, dividido por sus grados de libertad, ( $\mathrm{k}-1), \mathrm{MS}_{\mathrm{M}}$. La Tabla 1 muestra las diferentes expresiones para calcular las sumas de cuadrados y las correspondientes varianzas.

Tabla 1. Expresiones para el cálculo del ANOVA de un factor

\begin{tabular}{ccccc}
\hline Fuente & Suma de Cuadrados & $\begin{array}{c}\text { Grados de } \\
\text { Libertad }\end{array}$ & Varianza & $F_{\text {cal }}$ \\
\hline $\begin{array}{c}\text { Muestras o } \\
\text { Tratamientos }\end{array}$ & $S_{.}=\sum_{k=1}^{K} n_{k}\left(\bar{x}_{k}-\overline{\bar{x}}\right)^{2}$ & $\mathrm{k}-1$ & $M S_{M}=\frac{S S_{M}}{K-1}$ & $F=\frac{M S_{M}}{M S_{R}}$ \\
\hline Error & $S S_{\mathrm{R}}=\sum_{k=1}^{K} \sum_{j=1}^{n_{k}}\left(x_{k j}-\bar{x}_{k}\right)^{2}$ & $\mathrm{n}-\mathrm{k}$ & $M S_{\mathrm{R}}=\frac{S S_{\mathrm{R}}}{N-K}$ & \\
\hline & $S S_{\mathrm{T}}=\sum_{k=1}^{K} \sum_{j=1}^{n_{k}}\left(x_{k j}-\overline{\bar{x}}\right)^{2}$ & $\mathrm{n}-1$ & $M S_{\mathrm{T}}=\frac{S S_{\mathrm{T}}}{N-1}$ & \\
\hline
\end{tabular}

Nota: $\mathrm{K}$ indica el número de zonas y $\mathrm{N}$ el número total de resultados.

Se calcularon los valores de la tabla ANOVA, como $\mathrm{MS}_{M}$ y $\mathrm{MS}_{\mathrm{R}}$ son una medida de dispersión, se comparó con la una prueba de hipótesis $\mathrm{F}$. Si no existiera diferencia estadísticamente significativa entre ellas, la presencia de errores aleatorios sería la causa predominante de la discrepancia entre los valores medios. $\mathrm{Si}$, por el contrario, existiera algún error sistemático, $\mathrm{MS}_{\mathrm{M}}$ sería mucho mayor que $\mathrm{MS}_{\mathrm{R}}$, con lo cual el valor calculado de $\mathrm{F}$ sería mayor que el valor tabulado (F) para el nivel de significancia escogido y los grados de libertad considerados.

Por otro lado, para la identificación de la vegetación se tomaron como base los trabajos realizados por CONABIO (2017). Para lograr una mayor precisión se analizaron imágenes satelitales y se realizaron recorridos físicos. Para la representación de las pruebas y resultados se construyeron mapas que faciliten la identificación cartográfica de los componentes físicos y sociales del espacio geográfico a partir de imágenes satelitales, procesadas en el software ArcGIS 2010.

\section{Análisis de la problemática ambiental}

Se realizaron entrevistas a profundidad con actores clave en abril de 2019, con base en los conceptos socioambientales identificados en las etapas anteriores y considerados elementales para el diseño de escenarios, cada una tuvo una duración aproximada de cuarenta minutos. Las cuatro entrevistas fueron grabadas y transcritas para su posterior codificación y análisis en 


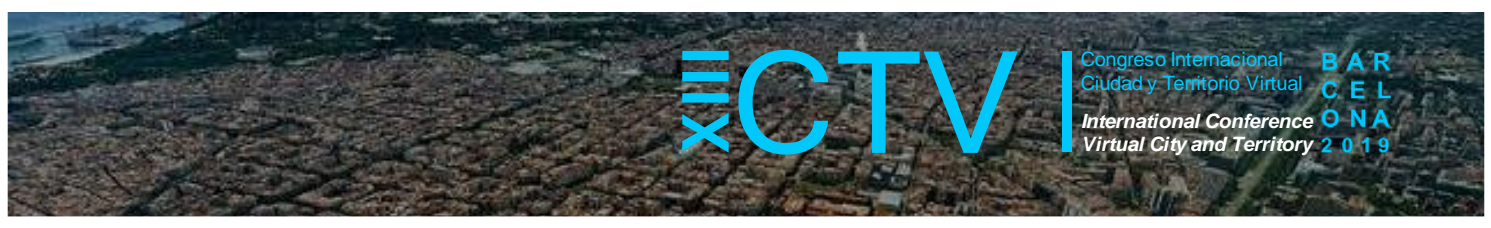

el software Atlas.ti. A las variables identificadas con mayor presencia y concurrencia (relación con otras variables).

\section{Evaluación}

Finalmente, se evaluó el comportamiento de la producción pesquera mediante series de tiempo en el programa Minitab, para determinar la posible evolución por especie.

\subsection{Resultados}

\section{a) Caracterización socioeconómica}

El factor antrópico y el proceso de urbanización son variables críticas en los procesos de conservación de humedales (Senhadji-Navarro, 2017). Las localidades ubicadas al noreste de la laguna presentan una dinámica social, económica y cultural de alta similitud, cuyo centro es el cuerpo de agua y los recursos que les proporciona, así como la no inclusión a la zona turística Diamante. Estas localidades son San Pedro Las Playas, Varadero de Tres Palos, La Estación, Laguna de El Quemado, Col. 10 de abril, Nicolás Bravo, El Arenal, Candelilla (Las Palmitas) y Barra Vieja. Asimismo, se han construido unidades habitacionales como Fraccionamiento Paraíso Diamante (Mapa Digital de México, 2015); en la figura 2 se aprecia su localización.

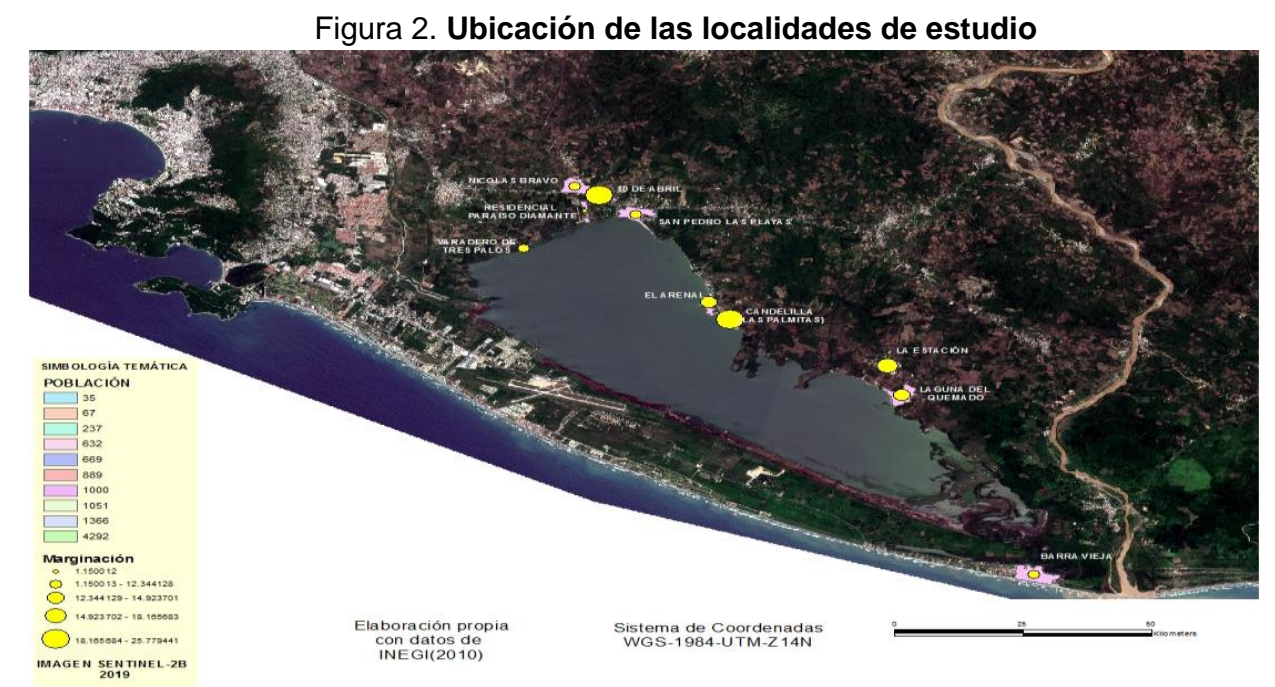

Fuente: Elaboración propia.

La población total en las localidades de estudio asciende a 10,238 hab, distribuida de manera uniforme entre hombres $(5,091)$ y mujeres $(5,147)$. La localidad más poblada es San Pedro Las Playas con 4,292 hab. La Población Económicamente Activa (PEA) representa a los habitantes mayores de 12 años que trabajan o buscan trabajo, está conformada por 3,984 personas, $38.9 \%$ del total.

Cabe resaltar que $97.8 \%$ de la PEA está ocupada y sólo el $2.2 \%$ (88 hab) no desempeña alguna actividad. Existen 3,018 viviendas particulares, de las cuales $78 \%$ están habitadas, la localidad con la de mayor cantidad es San Pedro Las Playas con 1,230 viviendas, 79\% están habitadas. 


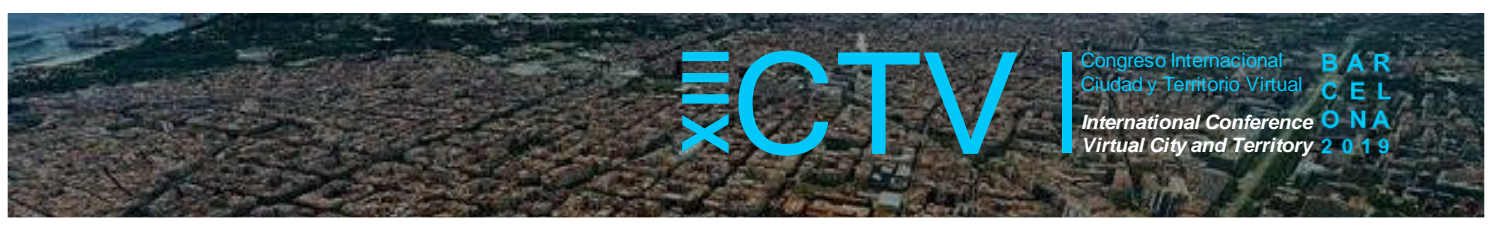

De las viviendas particulares habitadas, el $99.2 \%$ dispone de energía eléctrica; sin embargo, los servicios públicos no son óptimos: $53 \%$ no dispone de agua entubada dentro de la vivienda y ninguna posee servicio de drenaje. En la mayoría de las viviendas el agua se extrae de pozos artesanos y se utilizan fosas sépticas, con excepción de Residencial Paraíso Diamante, donde las viviendas cuentan con un sistema de drenaje que se canaliza a una planta tratadora dentro del conjunto (no existen datos sobre el funcionamiento de la planta). Además, $40 \%$ de las viviendas del área de estudio no dispone de un excusado al interior, $29 \%$ no cuenta con refrigerador y $33 \%$ posee piso de tierra. Los datos más severos los presenta Candelilla, donde $94 \%$ de las viviendas no dispone de agua entubada ni excusado, y $88 \%$ cuenta con piso de tierra. Las localidades que presentan los niveles más altos de marginación son Candelilla y Varadero de Tres Palos (CONAPO, 2010).

El acceso a los servicios de salud pública no forma parte del Índice de Marginación, sin embargo, representa un gasto importante para la población y una causa de empobrecimiento. En el caso de las localidades de estudio, el $57 \%$ de la población no está inscrito en algún sistema de salud pública.

Las principales actividades de la población son agricultura, turismo, y la más relevante es la pesca. El comercio de la zona está centrado en los productos pesqueros y en la venta de herramientas y servicios relacionados con la pesca; las especies de mayor importancia son: popoyote (Dormitator latifrons), cuatete (Arius guatemalensis), tilapia (Oreochromis niloticus), lisa (Mugil curema), charra (cichlasoma trimaculatum) y los menores como robalo (Centropomus nigriscens), huevina (Eleotris pictus) y pijolín (Centropomus robalito).

\section{b) Caracterización física}

La laguna es un cuerpo de agua somera con una profundidad promedio de $2 \mathrm{~m}$, en su punto más hondo alcanza $6 \mathrm{~m}$. En la desembocadura del Río de la Sabana y la franja central de la zona norte, el fondo está compuesto por lodos de hasta $90 \mathrm{~cm}$ de espesor. En la zona sur y en los extremos, la composición del fondo es arena fina. La figura 3 muestra estas variaciones.

Figura 3. Batimetría de la Laguna de Tres Palos

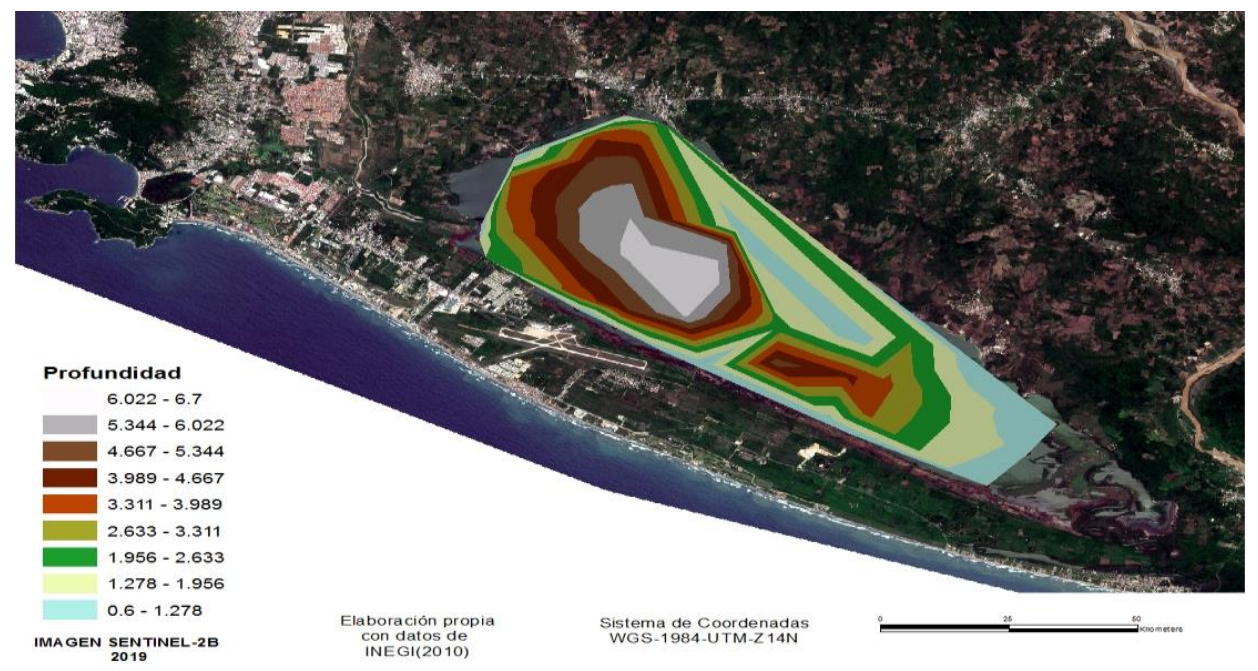

Fuente: Elaboración propia. 


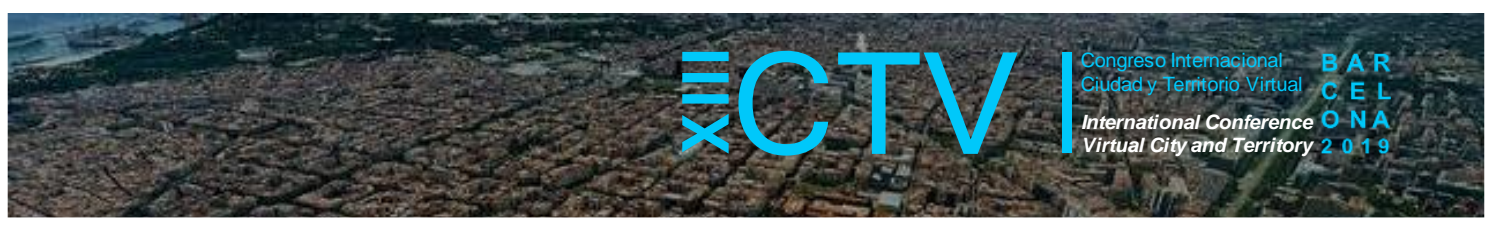

Con la finalidad de determinar las condiciones generales del cuerpo hídrico, se analizaron veinte muestras de agua a las que se les aplicaron parámetros de campo: salinidad, conductividad eléctrica $(\mathrm{mu} / \mathrm{cm})$, sólidos disueltos totales (SDT) $(\mathrm{mg} / \mathrm{l})$, turbiedad, (UTN), temperatura $\left({ }^{\circ} \mathrm{C}\right)$ y $\mathrm{pH}$. Los resultados promedio por zona se muestran en la tabla 3 .

Tabla 3. Resultados de los parámetros de campo

\begin{tabular}{lrrr}
\hline Parámetros de campo & \multicolumn{2}{c}{$\begin{array}{c}\text { Desembocadura del } \\
\text { Río de la Sabana }\end{array}$} & \multicolumn{2}{c}{ Zona Surte } \\
& 31.07 & 28.80 & 30.14 \\
\hline Temperatura $\left({ }^{\circ} \mathrm{C}\right)$ & 8.88 & 8.82 & 8.88 \\
\hline $\mathrm{pH}$ & 2.03 & 1.97 & 2.15 \\
\hline Salinidad & 3839.78 & 3733.88 & 4056.48 \\
\hline Conductividad $(\mu \mathrm{S} / \mathrm{cm})$ & 1882.44 & 1830.08 & 1988.30 \\
\hline SDT $(\mathrm{mg} / \mathrm{L})$ & 31.07 & 9.65 & 21.20 \\
\hline Turbiedad $($ UTN) & &
\end{tabular}

Nota: Promedio de los datos obtenidos en las pruebas de parámetros de campo tomadas en la laguna.

Fuente: elaboración propia

Los resultados y las diferencias en el paisaje sugirieron que la laguna no es homogénea. Por tanto, se aplicó un análisis de varianza (ANOVA), para determinar si hay diferencias entre zonas. Para cada uno de los seis parámetros de campo, la prueba de hipótesis para la diferencia de las medias con un nivel de confianza del $90 \%$ es la siguiente:

$\mu_{1}=$ Media poblacional del parámetro en la desembocadura del Río de la Sabana.

$\mu_{2}$ = Media poblacional del parámetro en la zona norte.

$\mu_{3}=$ Media poblacional del parámetro en la zona sur.

Con un $\alpha=10 \%$ o 0.1 , se encontró el valor crítico para el modelo del parámetro:

$F_{3-1,19-3,0.1}=2.688$ para la temperatura $y$

$F_{3-1,20-3,0.1}=3.5915$ para el resto de los parámetros

Las tablas de la 2 a la 7 muestran los resultados de los parámetros descritos en la Tabla 3.

Tabla 2. Tabla ANOVA para el parámetro Temperatura $\left({ }^{\circ} \mathrm{C}\right)$

\begin{tabular}{lrrrrrr}
\hline $\begin{array}{l}\text { Origen de las } \\
\text { variaciones }\end{array}$ & $\begin{array}{c}\text { Suma de } \\
\text { cuadrados }\end{array}$ & $\begin{array}{c}\text { Grados de } \\
\text { libertad }\end{array}$ & $\begin{array}{c}\text { Promedio de } \\
\text { los cuadrados }\end{array}$ & F & Probabilidad & $\begin{array}{c}\text { Valor crítico } \\
\text { para } F\end{array}$ \\
\hline Entre grupos & 13.8206 & 2 & 6.2293 & 21.8373 & 0.0001549 & 2.668 \\
\hline Error & 7.6488 & 16 & 0.2852 & & & \\
\hline Total & 21.4695 & 18 & & & & \\
\hline
\end{tabular}

Nota: Elaboración propia a partir de los parámetros de campo y el ANOVA

Tabla 3. Tabla ANOVA para el parámetro $\mathbf{p H}$

\begin{tabular}{lrrrrrr}
\hline $\begin{array}{l}\text { Origen de las } \\
\text { variaciones }\end{array}$ & $\begin{array}{c}\text { Suma de } \\
\text { cuadrados }\end{array}$ & $\begin{array}{c}\text { Grados de } \\
\text { libertad }\end{array}$ & $\begin{array}{c}\text { Promedio de } \\
\text { los cuadrados }\end{array}$ & F & Probabilidad & $\begin{array}{c}\text { Valor crítico } \\
\text { para F }\end{array}$ \\
\hline Entre grupos & 0.2798 & 2 & 0.13990 & 3.23 & 0.06462 & 3.5915 \\
\hline $\begin{array}{l}\text { Dentro de los } \\
\text { grupos }\end{array}$ & 0.7359 & 17 & 0.04328 & & & \\
\hline Total & 1.01571 & 19 & & & & \\
\hline
\end{tabular}

Nota: Elaboración propia a partir de los parámetros de campo y el ANOVA 
Tabla 4. Tabla ANOVA para el parámetro salinidad

\begin{tabular}{lrrrrrr}
\hline $\begin{array}{l}\text { Origen de las } \\
\text { variaciones }\end{array}$ & $\begin{array}{c}\text { Suma de } \\
\text { cuadrados }\end{array}$ & $\begin{array}{c}\text { Grados de } \\
\text { libertad }\end{array}$ & $\begin{array}{c}\text { Promedio de los } \\
\text { cuadrados }\end{array}$ & F & Probabilidad & $\begin{array}{c}\text { Valor crítico } \\
\text { para F }\end{array}$ \\
\hline Entre grupos & 0.14329 & 2 & 0.07164 & 4.6206 & 0.024971 & 3.5915 \\
\hline $\begin{array}{l}\text { Dentro de los } \\
\text { grupos }\end{array}$ & 0.26360 & 17 & 0.01550 & & & \\
\hline Total & 0.40689 & 19 & & & & \\
\hline
\end{tabular}

Nota: Elaboración propia a partir de los parámetros de campo y el ANOVA

Tabla 5. Tabla ANOVA para el parámetro conductividad

\begin{tabular}{llrrrrr}
\hline $\begin{array}{l}\text { Origen de las } \\
\text { variaciones }\end{array}$ & $\begin{array}{c}\text { Suma de } \\
\text { cuadrados }\end{array}$ & $\begin{array}{c}\text { Grados de } \\
\text { libertad }\end{array}$ & $\begin{array}{c}\text { Promedio de } \\
\text { los cuadrados }\end{array}$ & F & Probabilidad & $\begin{array}{c}\text { Valor crítico } \\
\text { para F }\end{array}$ \\
\hline Entre grupos & 451524.937 & 2 & 225762.468 & 4.6677 & 0.024223 & 3.5915 \\
\hline $\begin{array}{l}\text { Dentro de los } \\
\text { grupos }\end{array}$ & 822235.418 & 17 & 48366.7893 & & & \\
\hline Total & 1273760.35 & 19 & & & & \\
\hline
\end{tabular}

Nota: Elaboración propia a partir de los parámetros de campo y el ANOVA

Tabla 6. Tabla ANOVA para el parámetro SDT

\begin{tabular}{lcrrrrr}
\hline $\begin{array}{l}\text { Origen de las } \\
\text { variaciones }\end{array}$ & $\begin{array}{c}\text { Suma de } \\
\text { cuadrados }\end{array}$ & $\begin{array}{c}\text { Grados de } \\
\text { libertad }\end{array}$ & $\begin{array}{c}\text { Promedio de } \\
\text { los cuadrados }\end{array}$ & F & Probabilidad & $\begin{array}{c}\text { Valor crítico } \\
\text { para F }\end{array}$ \\
\hline Entre grupos & 108529.083 & 2 & 54264.541 & 4.6622 & 0.02430 & 3.5915 \\
\hline $\begin{array}{l}\text { Dentro de los } \\
\text { grupos }\end{array}$ & 197863.673 & 17 & 11639.039 & & & \\
\hline Total & 306392.756 & 19 & & & & \\
\hline
\end{tabular}

Nota: Elaboración propia a partir de los parámetros de campo y el ANOVA

Tabla 7. Tabla ANOVA para el parámetro turbiedad.

\begin{tabular}{lcrrrrr}
\hline $\begin{array}{c}\text { Origen de las } \\
\text { variaciones }\end{array}$ & $\begin{array}{c}\text { Suma de } \\
\text { cuadrados }\end{array}$ & $\begin{array}{c}\text { Grados de } \\
\text { libertad }\end{array}$ & $\begin{array}{c}\text { Promedio de los } \\
\text { cuadrados }\end{array}$ & F & Probabilidad & $\begin{array}{c}\text { Valor crítico } \\
\text { para F }\end{array}$ \\
\hline Entre grupos & 1161.9131 & 2 & 580.9565 & 70.2525 & $6.05 \mathrm{E}-09$ & 3.5915 \\
\hline $\begin{array}{l}\text { Dentro de los } \\
\text { grupos }\end{array}$ & 140.58215 & 17 & 8.26953 & & & \\
\hline Total & 1302.4952 & 19 & & & & \\
\hline
\end{tabular}

Nota: Elaboración propia a partir de los parámetros de campo y el ANOVA

En general, se observa que únicamente para el valor del pH se acepta la hipótesis nula, en los otros cinco parámetros se rechaza y se acepta la hipótesis alternativa demostrando que existen diferencias estadísticamente significativas entre las tres zonas de la laguna, como se observa en la Tabla 8.

Tabla 8: Tabla de resultados

\begin{tabular}{lllcl}
\hline \multicolumn{1}{c}{ Parámetro } & \multicolumn{1}{c}{$\mathrm{F}$} & Probabilidad & Valor crítico para F & \multicolumn{1}{c}{ Resultado } \\
\hline Temperatura $\left({ }^{\circ} \mathrm{C}\right)$ & 21.8373 & 0.0001549 & 2.668 & Rechazo Ho \\
\hline $\mathrm{pH}$ & 3.23 & 0.006462 & 3.5915 & Se acepta Ho \\
\hline Salinidad & 4.620685 & 0.024971 & 3.5915 & Rechazo Ho \\
\hline Conductividad $(\mu \mathrm{S} / \mathrm{cm})$ & 4.6677 & 0.0242 & 3.5915 & Rechazo Ho \\
\hline SDT $(\mathrm{mg} / \mathrm{L})$ & 4.6622 & 0.02430 & 3.5915 & Rechazo Ho \\
\hline Turbiedad $(\mathrm{UTN})$ & 70.2525 & $6.05 \mathrm{E}-09$ & 3.5915 & Rechazo Ho
\end{tabular}

Nota: Elaboración propia a partir de los parámetros de campo y el ANOVA aplicado con una Ho: $\mu_{1}=\mu_{2}=\mu_{3}$ y una $\mathrm{H}_{1}$ : $\mathrm{Al}$ menos una $\mu_{\mathrm{k} \neq} 0$; cuando $\mathrm{f}>\mathrm{fcrítica}=$ diferencia significativa entre las muestras. 


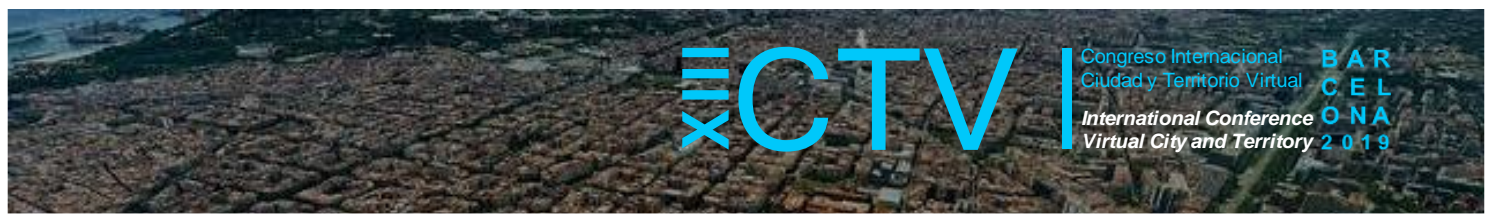

Las diferencias se explican en relación con las características físicas de cada zona, la desembocadura del Río de la Sabana (3 muestras) es somera y presenta mayor turbiedad con la entrada del afluente y aporte de materia orgánica, así como residuos sólidos; la zona norte (8 muestras) presenta una mayor profundidad (hasta de $6 \mathrm{~m}$ ) y mayor corriente, por lo que la salinidad es baja, así como el promedio de la temperatura; la zona sur (9 muestras) presenta menor grado de eutrofización, mayor vegetación y por ser la más cercana al canal que conecta con el mar, la conductividad es alta en función de los SDT y la salinidad. En la figura 4 se observan las diferencias entre zonas en el parámetro temperatura.

Figura 4. Condiciones generales del agua de la Laguna de Tres Palos

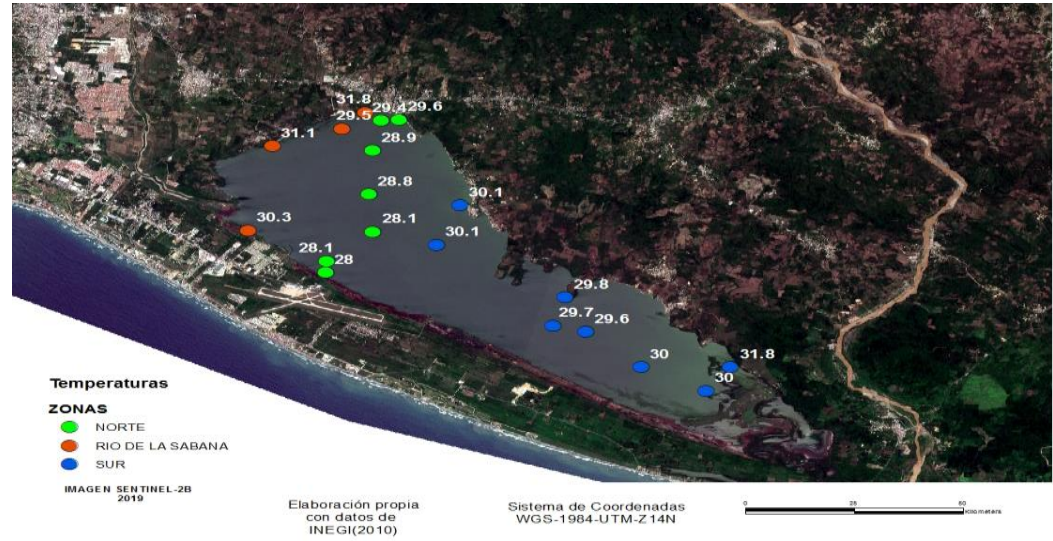

Fuente: Elaboración propia.

La zona de estudio presenta una vegetación formada principalmente por:

- Manglar: mangle blanco (Laguncularia racemosa) y mangle negro (Avicennia germinans).

- Manglar perturbado: cubierta forestal perturbada por eventos meteorológicos y por la construcción de infraestructura y zonas habitacionales.

- Otros humedales: vegetación hidrófita de Tular-Carrizal.

La cubierta de manglar sufrió una pérdida de 120 ha de 1979 a 2003 al sureste de la laguna (SAGARPA, 2004), sin que a la fecha se haya recuperado (CONABIO, 2017); por el contrario, la construcción de desarrollos inmobiliarios continúa. Actualmente, la vegetación se distribuye como se observa la figura 5 .

Figura 6. Distribución de la vegetación

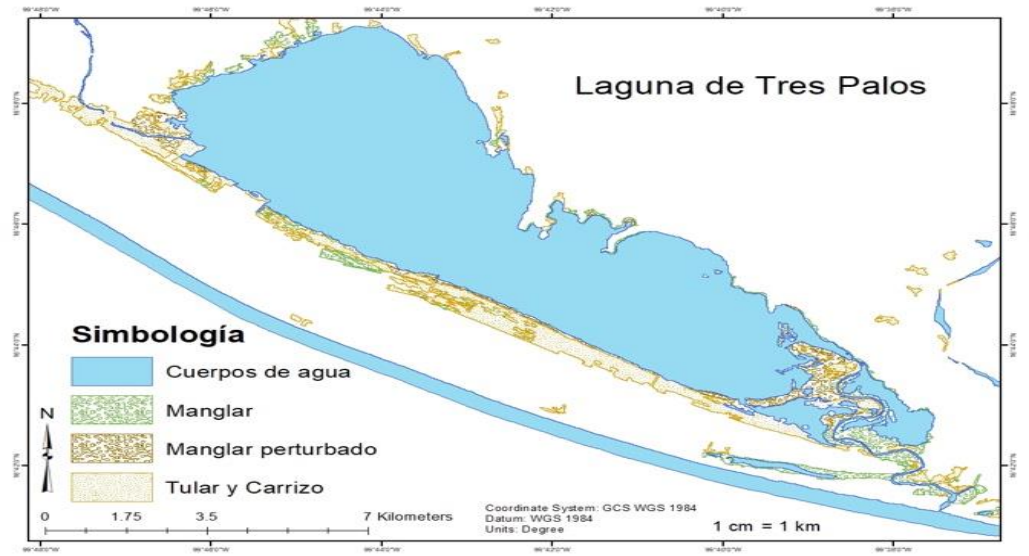

Fuente: Elaboración propia con información de CONABIO (2018). 


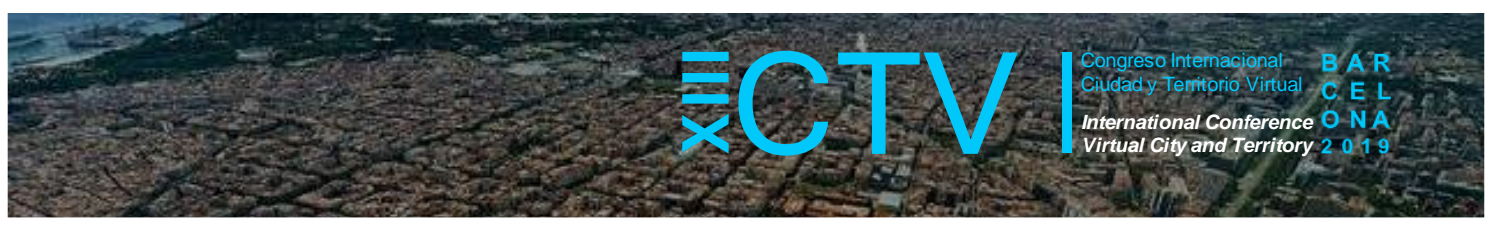

La restauración de la vegetación ribereña es un factor clave para aumentar la resistencia y resiliencia de los humedales, además de mejorar la condición de los suelos, la reproducción de organismos bentónicos y el restablecimiento de redes tróficas (Pires et al., 2017). Lo anterior, se traduce en beneficios directos para los pobladores, al aumentar su producción pesquera, obtener mejoras en el paisaje y protección contra inundaciones.

\section{c. Problemática ambiental}

La problemática ambiental se agudiza a causa de la deforestación del manglar, el azolvamiento que ha trastocado el intercambio mar-laguna y, sobretodo, la sobrepesca. La utilización de artes de pesca como trasmallos afectan los ciclos ecológicos y redes tróficas (Zarza-González y Gómez-Quesada, 2011); además, contribuyen a la pérdida de biodiversidad y disminución de la productividad pesquera, afectando la seguridad alimentaria.

Los conflictos de distribución ecológica pueden valorarse con más precisión si se distingue el ámbito espacial desde el cual éstos operan y la forma en la que los procesos los afectan de manera desigual (Brenner y Vargas-Del Río, 2012). Se contactó personalmente a los actores clave identificados: presidentes de cooperativas pesqueras y líderes de las comunidades, así como al Presidente del Consejo de Cuenca del Estado de Guerrero. Este acercamiento resultó adecuado para explicar los procesos socio-espaciales complejos relacionados con el problema ambiental de la Laguna de Tres Palos, sus efectos en las poblaciones y posibles vías de solución.

En las entrevistas con los pescadores se preguntó su percepción sobre los cambios en aspectos físicos de la Laguna como la biodiversidad, la fauna y flora, procesos urbanísticos y, sobretodo, la relación con la Laguna como medio para el desarrollo de sus actividades. Los entrevistados identificaron como principal fuente de contaminación al afluente del Río de la Sabana. Los códigos con un mayor número de menciones y relaciones con otros códigos (concurrencia) son los que se señalan en la Tabla 9. El código problema ambiental es el repetido con mayor frecuencia por los actores y con mayor relación con el resto de las variables, seguido por contaminación y pesca.

Tabla 9. Códigos identificados y su concurrencia

\begin{tabular}{lclc}
\multicolumn{1}{c}{ Códigos } & Concurrencia & \multicolumn{1}{c}{ Códigos } & Concurrencia \\
\hline Problema ambiental & 3.81 & Urbanización & 1.41 \\
\hline Contaminación & 2.79 & Corrupción & 1.32 \\
\hline Pesca & 2.36 & Pérdida de biodiversidad & 1.30 \\
\hline Contaminación hídrica & 2.34 & Gestión de recursos naturales & 1.28 \\
\hline Gobernabilidad & 1.97 & Residuos sólidos & 1.27 \\
\hline Vulnerabilidad & 1.87 & Cambio de uso de suelo & 1.23 \\
\hline Presión económica & 1.79 & Salud & 1.15 \\
\hline Calidad de vida & 1.77 & Región & 0.96 \\
\hline Gobernanza & 1.77 & Cooperativa pesquera & 0.90 \\
\hline Riesgo & 1.77 & Educación ambiental & 0.82 \\
\hline Deforestación de manglar & 1.67 & Percepción ambiental & 0.80 \\
\hline Apoyos gubernamentales & 1.66 & Emigración & 0.72 \\
\hline Gestión comunitaria & 1.58 & Costo de oportunidad & 0.45 \\
\hline
\end{tabular}

Nota: La codificación se realizó a partir de las entrevistas y se procesó en el software Atlas ti 


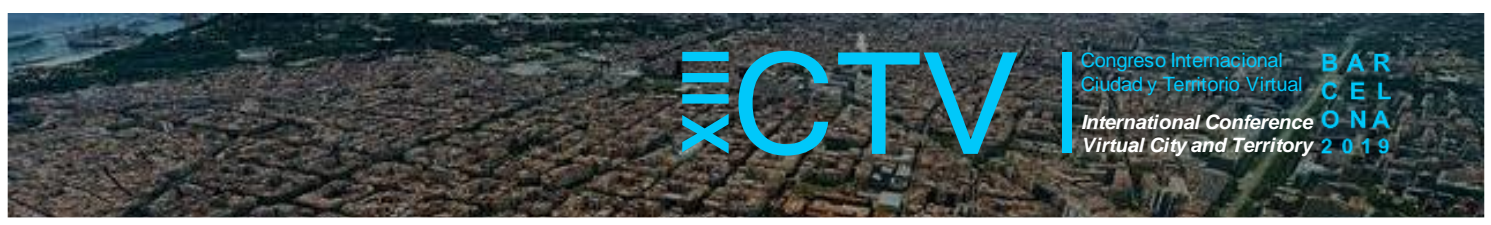

Las percepciones de los entrevistados fueron negativas. Con respecto al ambiente, los actores señalaron pérdida de especies de importancia pesquera; reducción de tamaño en las existentes (róbalo, tilapia, lisa); y deforestación de manglar. En lo social, los pescadores expusieron que el aumento de población y de cooperativas pesqueras han generado mayor presión ecológica y económica sobre el medio, disminuyendo su ingreso y calidad de vida.

En resumen, la contaminación presente en la laguna proviene de dos fuentes: el afluente del Río de la Sabana y los procesos de urbanización que se realizan en los márgenes de la Laguna, como se observa en la figura 8.

Figura 8. Causas y consecuencias de la contaminación en la Laguna de Tres Palos

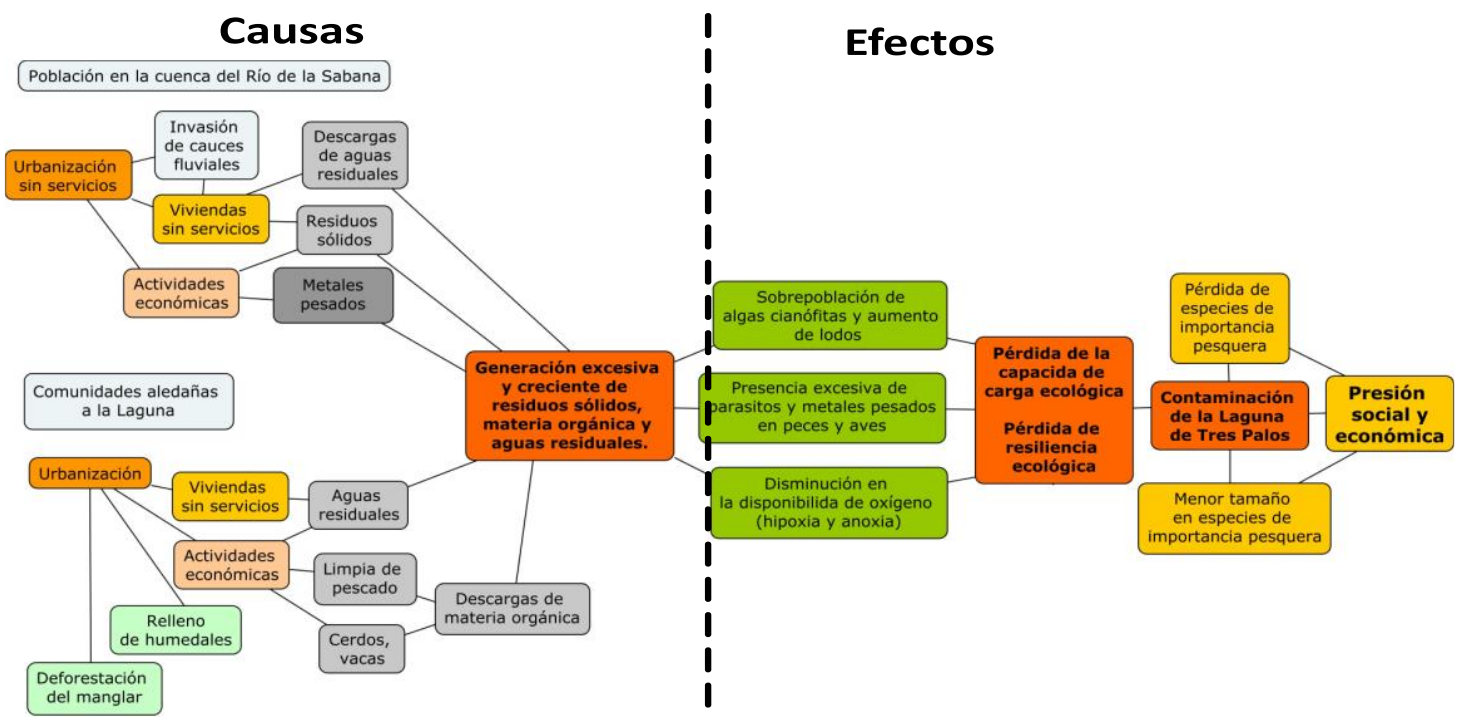

Fuente: Elaboración Propia

c) Series de tiempo de la producción pesquera

En relación con la producción pesquera, se obtuvieron resultados opuestos, por un lado, la producción de especies resistentes como el popoyote y la tilapia han aumentado, mientras que especies con mayor valor comercial como el robalo, la lisa y el charal han disminuido considerablemente. Las perspectivas de producción de la tilapia y el robalo se detallan en la figura 9.

Figura 9. Serie de tiempo para la producción de la Tilapia y Robalo
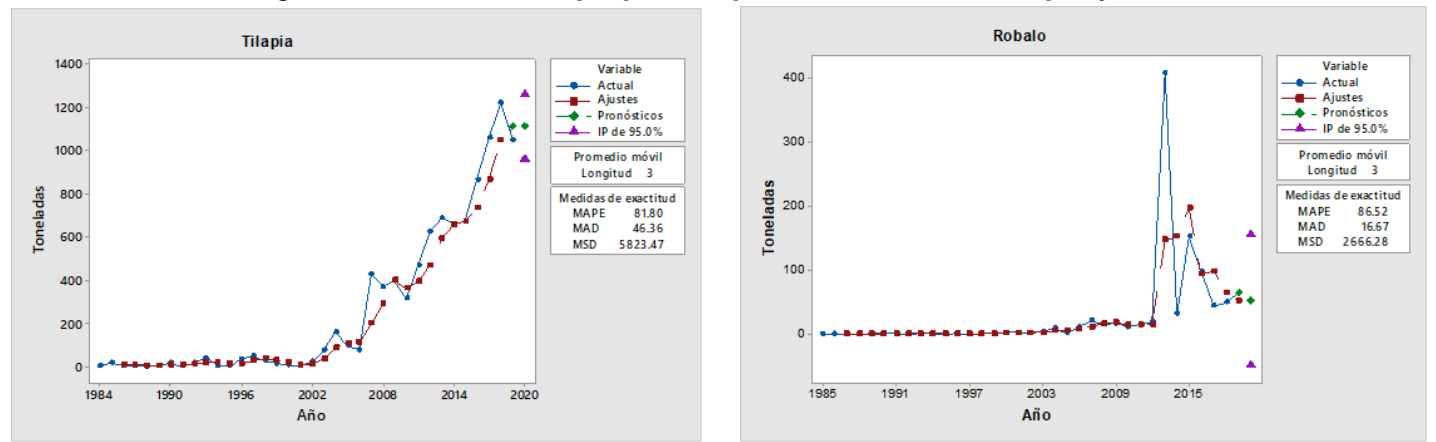

Fuente: Elaboración propia a partir de las bases de datos CONAPESCA, 2018. 


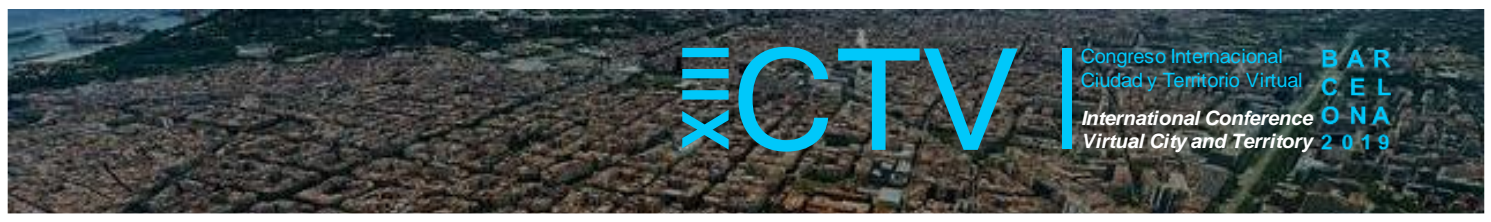

En el caso de la tilapia, la productividad creciente se explica por el aumento de granjas acuícolas en la laguna, mientras que el robalo es más sensible a los cambios en el ambiente y más valorado en la pesca.

\section{Conclusiones}

La Laguna de Tres Palos es un ambiente complejo con múltiples relaciones entre los factores físicos y los socioeconómicos. La región ha generado su propia identidad a través de los procesos económicos, sociales y culturales que realizan los habitantes, quienes son responsables de la contaminación del cuerpo de agua, de la desaparición de especies y de la transformación del paisaje y, a su vez, tienen la capacidad de revertir el daño, mejorar sus condiciones y conservar el ambiente para las generaciones venideras, a través de procesos más eficientes y sustentables.

Los resultados concluyen que no existen, por el momento, estructuras y mecanismos capaces de conciliar los conflictos entre los diferentes actores. Se evidencia la presencia de programas y apoyos gubernamentales en diversos sentidos; sin embargo, la evidencia confirma el incumplimiento de normas y la debilidad de las instituciones.

Es necesario construir soluciones al problema ambiental que presenta la Laguna de Tres Palos basados en mecanismos eficientes de gobernanza ambiental para la preservación del medio y el desarrollo de las poblaciones vecinas.

Agradecimientos: Esta ponencia deriva de una investigación doctoral financiada por CONACYT (Consejo Nacional de Ciencia y Tecnología). Asimismo, se agradece al Ing. Enrique Jesús Flores Munguía por brindar apoyo técnico y facilitar el uso del Laboratorio de Análisis Químicos Ambientales (LABQAM) del Doctorado en Ciencias Ambientales), y a los estudiantes Trinidad Esmeralda Vilchis Pérez y Luis Miguel Moctezuma Teresa por su apoyo en la aplicación de entrevistas.

Contribuciones de los autores: El primer autor conceptualizó y desarrolló la investigación (incluido el trabajo de campo); el segundo autor revisó la escritura y edición y analizó los resultados; el tercer y quinto autor desarrollaron y validaron los métodos estadísticos; el cuarto autor apoyó en el diseño metodológico.

Conflicto de Intereses: Los autores declaran que no hay conflicto de intereses.

\section{Bibliografía}

Brenner, L., y Vargas-del-Río, D. (2012). Community-based ecotourism and environmental protection in Mexico: a synergetic strategy or trendy slogan. Tourism: developments, issues and challenges Nova Science Publishers, New York, 255-84.

Comisión Nacional de Acuacultura y Pesca (CONAPESCA) Delegación Guerrero. (2018). Bases de datos de la producción pesquera en la Laguna de Tres Palos. México. 


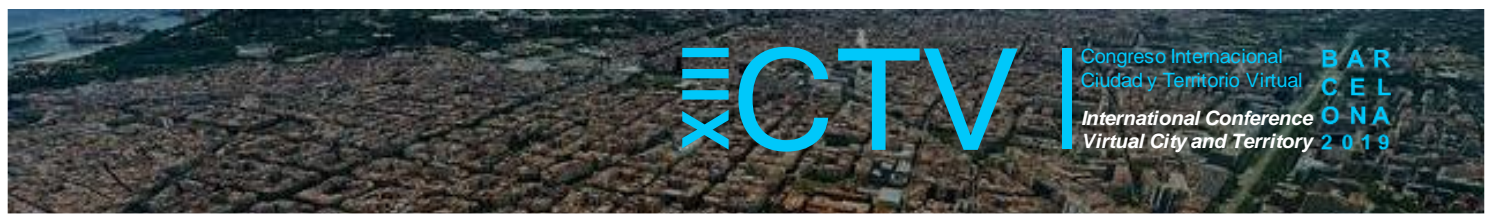

De la Lanza, G., Alcocer, J., Moreno, J.L., Hernández Pulido, S. (2008). Análisis químicobiológico para determinar el estatus trófico de la Laguna de Tres Palos, Guerrero, México. Hidrobiológica, vol. 18, núm. 1, pp. 21-30

García, E. (1973). Modificaciones al sistema de clasificación climática de Koppën. Instituto de Geología, UNAM, México.

Giddens, A. (2010). La política del cambio climático. Alianza Editorial, Madrid.

Gil, J.S. (2005). Sobreexplotación de las pesquerías en la Laguna de Tres Palos, Guerrero, México. Tesis de Maestría. UCDR., U.A.G. 149p.

Godet, M., \& Durance, P. (2007). Prospectiva Estratégica: problemas y métodos. Cuadernos de LIPSOR, 104.

Consejo Nacional de Población (CONAPO). (2015). Índice de marginación por entidad federativa y municipio. México.

Instituto Nacional de Estadística y Geografía (INEGI). (2010). Censo de Población y Vivienda.

Instituto Nacional de Estadística y Geografía (INEGI). (2015). Mapa Digital de México.

Recuperado en: https://www.inegi.org.mx/temas/mapadigital/

Jones, P. (2017). The Futures of Canadian Governance: Foresight Competencies for Digital Public, Canadian Public Administration Journal, Canadá.

Mendoza Mojica, M., Martínez Arroyo, A., Espinosa Fuentes, M., Peralta Rosales, O., \& Castro Romero, T. (2013). Caracterización de dos lagunas del Pacífico tropical mexicano en relación con el contenido de carbono y la captura y emisión de $\mathrm{CH} 4$ y CO2. Revista Internacional de Contaminación Ambiental, 29(2), pp. 145-154.

Ortiz, F. (2014). Caracterización de la contaminación en la Laguna de Tres Palos, Guerrero como consecuencia del desarrollo habitacional e industrial desordenado. Tesis doctoral.

Pires, A.P.F., Rezende, C.L., Assad, E.D., Loyola, R., Scarano, F.R. (2017). Forest restoration can increase the Rio Doce watershed resilience Perspect. Ecol. Conserv., 15, pp. 187-193,

Rosas-Acevedo, J. L., Sánchez-Infante, A., Rosas-Acevedo, A. Y., Castañón, W., Sampedro, L., \& Juárez, A. L. (2016). Acuatic Insects at Southeast of Wetlands in the Tres Palos Lagoon, Acapulco, Guerrero, Mexico. American Scientific Research Journal for Engineering, Technology, and Sciences

Ruiz, T. (2017). Análisis comparativo de índices de eutrofización en lagunas costeras del Estado de Sonora, México. Tesis doctoral.

Secretaría de Agricultura, Ganadería, Desarrollo Rural, Pesca y Alimentación (SAGARPA). (2004). Acuerdo mediante el cual se aprueba la actualización de la Carta Nacional Pesquera y su anexo. Publicado en el Diario Oficial de la Federación (DOF 15/03/2014). 


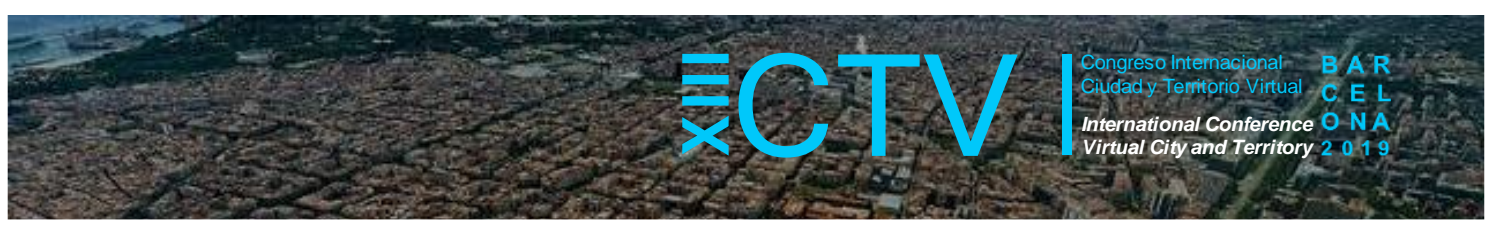

Senhadji-Navarro, K., Ruiz-Ochoa, M. A., \& Rodríguez Miranda, J. P. (2017). Estado ecológico de algunos humedales colombianos en los últimos 15 años: una evaluación prospectiva. Colombia forestal, 20(2), 191-200.

Valderrama, L. H., Rodríguez, M. T., Troche, C., Valázquez, S., Villeda, E., Alcántara, J.A., Vázquez, B., Cruz, M. I. y Ressl, R. (2017). Manglares de México: actualización y exploración de los datos del Sistema de monitoreo 1970/1980-2015. Comisión Nacional para el Conocimiento y Uso de la Biodiversidad (CONABIO), México, D.F. ISBN: 978-607-8328-78-9.

Violante-González, J., Marquez-Silva, E., Narnin y Monks, S., García-lbáñez, Sergio y PulidoFlores, G. y Rojas-Herrera, A. y Flores-Rodriguez, P. (2016). Population dynamics of the acanthocephalan Neoechinorhynchus brentnickoli (Neoechinorhynchidae) in Pacific fat sleeper, Dormitator latifrons, from Tres Palos Lagoon, Guerrero, Mexico. Invertebrate Reproduction \& Development. 61. pp. 1-7.

Winter, Kawika B., Lincoln, Noa K., Berkes, Fikret. (2018). The Social-Ecological Keystone Concept: A Quantifiable Metaphor for Understanding the Structure, Function, and Resilience of a Biocultural System. Sustainability 10, no. 9: 3294.

Zarza-González, E. \& Gómez-Quesada, J.C. (2011). Lagunas costeras e interiores. En: Zarza, E. (ed), El entorno ambiental del Parque Nacional Natural Corales del Rosario y San Bernardo (PNNCRSB). Primera edición: Colombia: Parques Nacionales Naturales de Colombia. pp. 148165. 